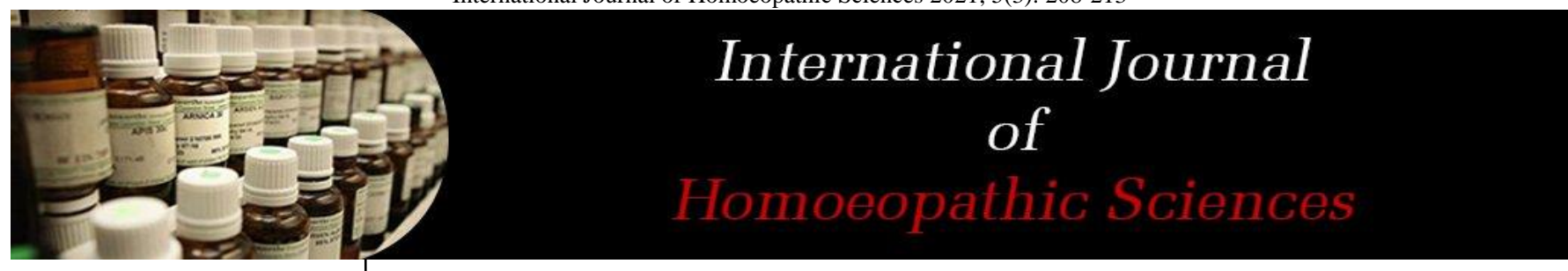

E-ISSN: $2616-4493$ P-ISSN: 2616-4485 www.homoeopathicjournal.com IJHS 2021; 5(3): 208-213 Received: 15-04-2021 Accepted: 03-06-2021

Dr. Siddhartha Pal N.I.H, Kolkata, J.R.F., Dr. Anjali Chatterjee Regional Research Institute, Kolkata, West Bengal, India

Dr. S Seetha Lakshmi PGT, Department of Organon of Medicine, National Institute of Homoeopathy, Kolkata, West Bengal, India
Corresponding Author: Dr. Siddhartha Pal N.I.H, Kolkata, J.R.F., Dr. Anjali Chatterjee Regional Research Institute, Kolkata, West Bengal, India

\section{An open label prospective clinical trial assessing the role of individualized homoeopathic medicine in management of adolescent depression}

\author{
Dr. Siddhartha Pal and Dr. S Seetha Lakshmi
}

DOI: https://doi.org/10.33545/26164485.2021.v5.i3d.424

\begin{abstract}
Background: "Depression-Let's talk" was the slogan for World Health Day 2017. Depression is an extremely common illness which contributes to significant disease burden at national and global levels, especially of the adolescent age group.

Objectives: To ascertain the role of homoeopathic medicines in the management of moderate depression in adolescent age group.

Material and Methods: 44 patients were enrolled. An open observational clinical trial was conducted at Out Patient Department of National Institute of Homoeopathy, Kolkata. HDRS-17 and PHQ-9 Score level was recorded at baseline, at 3 months and after 6 months of treatment for assessing the primary and secondary outcomes respectively. Medicines were prescribed on the basis of strict homoeopathic principles.

Result: 12 patients dropped-out, 32 patients completed the trial. Protocol-compliant sample $(n=32)$ was analyzed at the end. HDRS-17 Score Baseline Vs HDRS-17 Score at 3 months Vs HDRS-17 Score at 6 months: Mean was reduced from 15.5 (SD 3.464) to 8.81 (SD 2.78), to 8.71 (SD 3.87) 95\% CI 1.29 to 1.02 to $1.42, P<0.05$, [One way ANOVA test] was statistically significant over 6 months of treatment. PHQ-9 Score Baseline Vs PHQ-9 Score at 3-month Vs PHQ-9 Score at 6 months: Mean was reduced from 15.28 (SD 4.09) to 9.81 (SD 3.49), to 7.31 (SD 4.78), 95\% CI 1.51 to 1.30, to 1.74, $P$ < 0.05 , [One way ANOVA test] was statistically significant over 6 months of treatment.

Conclusion: The outcome of individualized homoeopathic treatment was found satisfactory with evidence of the overall improvement of the patients.
\end{abstract}

Keywords: Adolescent depression, CBT, HDRS-17 Score, PHQ-9 Score, Homoeopathic principle, Individualization

\section{Introduction}

Depression is presently one of the leading and burning public health issues in India, which has significant contribution in terms of morbidity, disability and even mortality, along with socioeconomic loss. Globally, on an around about 322 million people were affected by depression in $2015^{[1]}$. Depressive disorders are common especially in adolescents worldwide ${ }^{[2]}$ with an estimated 1 -year prevalence of $4-5 \%$ in mid to late adolescence ${ }^{[3,4]}$. It is the second to third important cause of suicide in adults and also in the adolescent age group [5, 6 , ${ }^{7]}$, as depression and suicide are closely interrelated ${ }^{[1]}$. It stands out to be the fourth major contributor for the Global Burden of Disease, in terms of DALYs ${ }^{[8]}$. As per NHMS (201516 ) in India, out of 20 every one person above 18 years of age, is suffering from depression, approximately amounting to a total of 45 million persons with depression in $2015^{[1]}$. It is not only the cause but also a consequence of a huge number of noncommunicable disease conditions, substance abuse and nutritional disorders. Not only this, but it is adversely related with infectious diseases like TB, HIV, etc ${ }^{[1]}$. This accounts for $15 \%$ of global DALYs attributable to mental, neurological and substance use disorders (31 million 11 DALYs) with depression one amongst them, which is accounting for $37 \%$ (11.5 million DSALYs) in $2013^{[9]}$. Depression also leads to serious social and educational impairments ${ }^{[10,}$ 11]. Nearly 30-60\% of patients with depression are reported to suffer from pain syndromes; and also increases the risk of early inflammatory arthritis. ${ }^{12} 2: 1$ is the prevalence ratio has been noted for unipolar depression between females to males in pubertal age group ${ }^{[13]}$.

Depression is defined as a cluster of specific symptoms with associated impairment. The clinical and diagnostic features of this disorder are broadly similar in adolescents and adults $[14,15]$. 
The two main classification systems, i.e., ICD-10 (International Classification of Diseases - 10) and DSM-V (the American diagnostic and statistical manual of mental disorders- V), defines depression similarly but DSM-V makes one exception for children and adolescents whereby irritable rather than depressed mood is allowed as a core diagnostic symptom ${ }^{[16]}$. Depression can further be identified by noting the change in the food habits and patterns, the more the depression the more the disordered food habits ${ }^{[17}$, ${ }^{18]}$. History of familial depression or exposure to stressful situations are the most robust factors contributing to development of depression [19]. Traumatic experiences in childhood, frequent migration, negative life events, educational setbacks, early relationship problems, family history of mental illness as well as stress at school and home are linked in varying degrees to lead into depression ${ }^{[20]}$. The ICD-10 code for depression in adolescents: F93.8. Symptoms need to be present for a minimum period of at least 2 weeks. The major symptoms are feeling sad or depressed most of the day, almost daily; indifferent to even loved ones and activities, most of the day; loss of energy or fatigue noted. The minor symptoms include loss of selfconfidence or self-esteem, unreasonable feelings of guilt every day, recurrent thoughts of death or suicidal behavior, diminished ability to think with bodily agitation or slowness with disturbed sleep patterns, gloomy and unhappy views of the future and increased or decreased appetite ${ }^{[21,22]}$.

Screening can be done using two questions ${ }^{[23]} \mathrm{a}$. In the past 2 weeks have you lost interest or pleasure which usually you like to do? b. Have you felt sad, low, down, depressed or hopeless in the past 2 weeks? If "yes" is the answer to either of the questions then further assessment needs to be done using various scales. The usual choice of treatment in depression includes antidepressant medications, psychotherapy, electroconvulsive therapy and light therapy; administered singly or in combination [24]. Cognitive behavior therapy and interpersonal therapy should be used for the treatment of mild depression. Cognitive Behavioral therapy refers to a class of interventions which share basic premise that both mental and psychological disorders are maintained by cognitive factors. Beck and Ellis pioneered this therapy. CBT is helpful for various conditions like depression, substance use disorder, schizophrenia, psychotic disorders, insomnia, personality disorders, female hormonal complications, etc. Modern medicine states Tricyclic antidepressants should not be used in treatment of childhood and adolescent depression [25] Fluoxetine (Prozac), Citalopram (Celexa) and Sertraline (Zoloft) are recommended as first line treatment for children and adolescent depression [26, 27, 28]. For prevention of depression, community approaches should be included like Life Skills Programs addressing concerns of children and adolescents to enhance cognitive, problem-solving and social coping skills; school-based awareness programs for the prevention of child abuse and substance abuse and interventions for parents of children with behavioral problems may reduce parental depressive symptoms and improve outcomes for their children ${ }^{[29]}$.

The treatment of mental health disorders such as depression, grief, anxiety and phobia are some of the significant features seen in the case load of homoeopathic practitioners. ${ }^{30}$ Homoeopathy has a well-established therapeutic system with potential relevance to psychiatry ${ }^{[31]}$. However, major questions have always aroused regarding the effectiveness and appropriate role of Homoeopathy in the management of depression, which are still unanswered ${ }^{[32]}$. There is a lack of high quality clinical trials in Homoeopathy and also incorporation of preference arms or uncontrolled observational trials to be methodologically suitable for further studies in this direction ${ }^{[33]}$. Systemic reviews of randomized placebo controlled studies with homoeopathic treatment in psychiatry do not preclude the possibility of some benefit ${ }^{[34]}$. Two double- blind, placebo-controlled trials, testing the efficacy of individually prescribed Homoeopathic medications, both failed to recruit a sufficient number of participants, thus preventing analysis of results or resulted in a premature ending of the trial ${ }^{[35]}$. In observational studies [31, 36] majority of patients who received treatment for depression from homoeopaths reported improvement. Twenty-seven cases studied in an open study on behavioral disorders, which was undertaken by the Central Council for Research in Homoeopathy also suggested improvement in depressive neurosis ${ }^{[37]}$. Although the results of the study were positive, but the study was not well-designed and was under-powered and lacked rigor. As the existing evidences remain minuscule, hence we aimed to generate some preliminary data in this aspect.

\section{Methods}

Setting and Design: A prospective, single-arm, nonrandomized, open label observational trial was conducted from October 2018 to October 2019 on 32 individuals suffering from adolescent depression at the Out Patient Department of National Institute of Homoeopathy, Kolkata. The proposed plan of work was approved by the Ethical Committee of the institution (Ref. F. No. 523/NIH/PG/Ethical Comm. 2009/Vol 5/2935; dated 27 September 2018). The trial however could not be registered. Each patient was provided with patient information sheet in local vernacular Bengali language detailing the objectives, methods, risks and benefits of participating and confidentiality issues. Before enrolment, written informed consent was taken from the patient and legal guardian.

\section{Inclusion \& Exclusion criteria}

Inclusion Criteria: 1. Patient willing to undergo homoeopathic treatment. 2. Patient of Adolescent age group suffering from depression. 3. Patient from different socioeconomic status. 4. Patient of all religion. 5. Patient who will score mild to severe on Patient Health Questionnaire (PHQ-9). 6. Patient who will score mild to severe on Hamilton Depression Rating Scale. 7. Patient giving voluntarily consent to participate.

Exclusion Criteria: 1. Patient not willing to participate in the study. 2. Patient who will score very severe in Hamilton depression rating scale. 3. Patients suffering from MDD not related to Adolescent period. 4. Persons who are too sick for consultation. 5. Patient not willing to undergo homoeopathic treatment. 6. Cases with substance abuse or any severe psychiatric illness. 7. Congenital anomaly and self-reported immune-compromised state.

\section{Outcome assessment}

- Primary outcome: will be assessed by Hamilton Depression Rating scale at baseline, 3 months and 6 months.

- Secondary outcome: It will be assessed using patient 
health questionnarie (PHQ-9) Scale at baseline, 3 months and 6 months.

\section{Intervention and follow-up}

All patients were given appropriate individualized homoeopathic medicines strictly based on homoeopathic principles. Patients were advised to take care of their lifestyle and diet. Cases were repertorized as per the need. Repetition was done depending on individual requirement of the case. Each patient was enrolled and intervened and follow up was done for 6 consecutive months, with the data noted at baseline, $3^{\text {rd }}$ and $6^{\text {th }}$ months respectively.

Statistical analysis: Frequency Distribution of the collected data was done following standard statistical methods and analyzed; data is presented in appropriate format. Analysis was done for varieties of clinical presentations \& effect of Homoeopathic prescription. Apart from the basic statistical methods of tabulation, graphical representations are also done. One way ANOVA is done to analyze the changes that occurred in the values of HDRS-17 and PHQ-9 in each patient as a result of the intervention. Data was analyzed from descriptive point of view.

\section{Results \\ Study flow}

A total of 71 patients were preliminarily screened on the basis of entry criterion of occurrence of Five (or more) of the symptoms-depressed mood, diminished interest or pleasure in all, weight gain or weight loss, insomnia or hypersomnia, psychomotor agitation or retardation, fatigue, loss of concentration, recurrent thoughts of death have been present during the same 2 -week period and represent a change from previous functioning; at least one of the symptoms is either (1) depressed mood or (2) loss of interest or pleasure. The HDRS-17 score high in 20 patients and 7 did not give consent.

Of which, 44 were assessed for eligibility and confirmed the diagnosis by clinical psychologist also. 12 patients are dropped out in between the study. Hence, only 32 patients were completed the study.

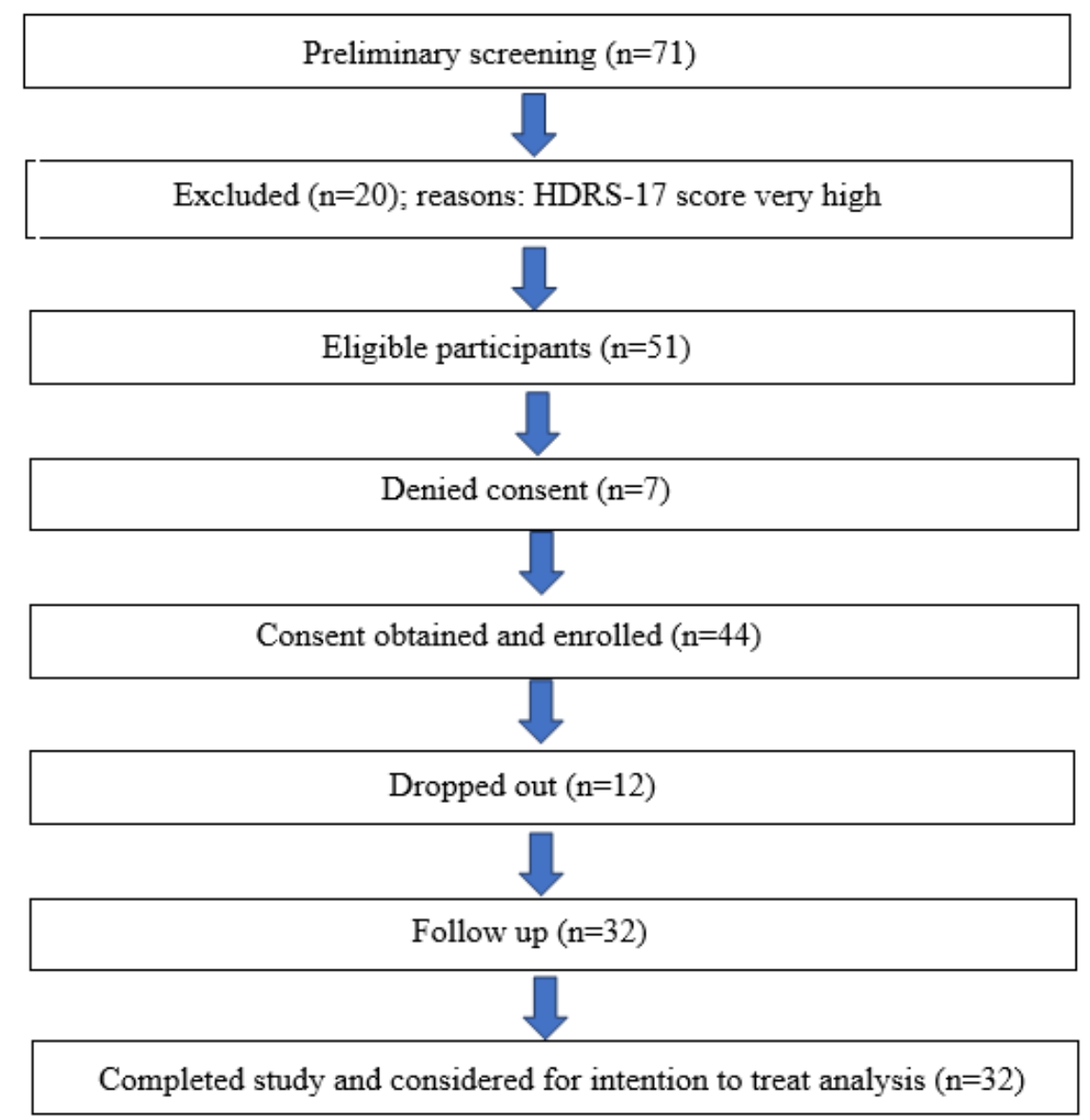

Fig 1: Study flow diagram

\section{Baseline Feature}

- The maximum number of patients belonged to the age group of $18-19$ years $(n=15 ; 48.87 \%)$ followed by $16-$ 17 years $(n=10 ; 31.25 \%), 13-15$ years $(n=6 ; 18.75 \%)$ and $10-12$ years $(n=1 ; 3.125 \%)$.

- $\quad$ Female patients are majority $(n=17 ; 53.12 \%)$.

- Majority of patients had non-vegetarian diet $(n=28$; $87.5 \%)$.

- The mean HDRS-17 score was 15.5 , with $34.37 \%$ $(\mathrm{n}=11)$ having mild depression, $40.62 \%(\mathrm{n}=13)$ having mild to moderate depression and $25 \%(\mathrm{n}=8)$ having moderate to severe depression. None of the patients were with score 20 and above.

- The mean PHQ-9 score was 15.28 , with $12.5 \% \quad(n=4)$ having mild depression, $21.87 \%(\mathrm{n}=7)$ having moderate depression, $53.12 \%(\mathrm{n}=17)$ having moderately severe and $12.5 \%(\mathrm{n}=4)$ having severe depression.

Baseline 3 months 6 months after treatment comparison: Among the 44 patients, only three patients had an increase 
of HDRS-17 score and PHQ-9 score after 6 months' followup and 12 patients dropped out of the study. HDRS-17 score mean value reduced from 15.5 (variance 12) to 8.81(variance 7.51) after 3 months of treatment and 15.5 (variance 12) to 8.71(variance 14.98) after 6 months of treatment. Mean reduction: $6.79,95 \%$ confidence interval 1.29 to 1.02 to $1.42, P<0.05$. F $(2,93)=40.07771, \mathrm{~F}$ critical value 3.094337. [One way ANOVA test]

PHQ-9 score mean value reduced from 15.28 (variance 16.78 ) to 9.81 (variance 12.22 ) after 3 months of treatment and 15.28 (variance 16.78) to 7.31(variance 22.86) after 6 months of treatment. Mean reduction: $7.9,95 \%$ confidence interval 1.51 to 1.30 to $1.74, \mathrm{P}<0.05$. $\mathrm{F}(2,93)=30.73616, \mathrm{~F}$ critical value 3.094337. [One way ANOVA test]

\section{Homoeopathic medicine used}

As per the totality of symptoms, at baseline, Pulsatilla nigricans was prescribed in 8 patients $(25 \%)$ and Natrum muriaticum was prescribed in 6 patients $(18.75 \%)$; Ignatia, Staphysagria, Causticum were prescribed in 3 patients (9.37\%) each. Sepia was prescribed in 2 patients $(6.25 \%)$ and Aurum metallicum, Mercurious, Sulphur, Mancinella, Phosphorus, Nux vomica, Psorinum were prescribed in 1 patient $(3.12 \%)$ each.

The indicated medicine was prescribed in different potencies as per the susceptibility of each individual patient and guidelines of Organon of medicine. Medicine was changed as per the demand of case, when there was no such marked improvement or totality of symptoms changed. Placebo was prescribed as long as improvement continued. Among the 32 patients, no change of medicine was required for 25 patients, though repetition or prescription of higher potencies was prescribed when the case stand still and the same potency was not enough to cure the case. The list of prescribed medicines and the indications of the most frequently remedies are given bellow.

\section{Indication of most frequently prescribed medicines}

1. Pulsatilla: Hypochondriacal moroseness; takes everything in bad part. Sullenness, breaking out into weeping, when interrupted in his work. Weeps easily. Highly emotional. Likes sympathy.

2. Natrum Muriaticum: Tearfulness, great sadness, joylessness. Unrequited affection brings on complaints. Indifferent and sad. Dislike of work. Every trifle excites him to anger. Wants to be alone to cry.

3. Sepia: Indifferent to those loved best. Averse to occupation, to family. Irritable; easily offended. Dreads to be alone. Very sad. Weeps when telling symptoms. Miserly.
4. Staphysagria: Impetuous, violent outburst of passion, hypochondriacal, sad. Dwells on sexual matters; prefers solitude. Peevishness and disinclination for mental work.

5. Ignatia Amara: Indifference to everything. Audacity. Slight blame or contradiction excites him to quarrel, and he is vexed at himself for doing so. Sighing and sobbing. After shocks, grief, disappointment. Broods in solitude over imaginary trouble.

6. Causticum: Sad, hopeless. Intensely sympathetic for suffering of others. Ailments from long-lasting grief, sorrow, sudden emotions, from anger or vexation. Melancholy mood. Indisposed to work. Constant scolding. Obstinacy.

Table 1: Socio-Demographic Profile of the Patients $(\mathrm{N}=32)$

\begin{tabular}{|c|c|}
\hline Characteristics & Estimates \\
\hline \multicolumn{2}{|c|}{ Age n (\%) } \\
\hline 10-12 years & $1(3.125)$ \\
\hline $13-15$ years & $6(18.75)$ \\
\hline 16-17 years & $10(31.25)$ \\
\hline 18-19 years & $15(48.875)$ \\
\hline \multicolumn{2}{|c|}{ Gender n (\%) } \\
\hline Male & $15(46.875)$ \\
\hline Female & $17(53.125)$ \\
\hline \multicolumn{2}{|c|}{ Economic Status n (\%) } \\
\hline Upper class & $4(12.5)$ \\
\hline Middle class & $15(46.875)$ \\
\hline Lower class & $13(40.625)$ \\
\hline \multicolumn{2}{|c|}{ Residence n (\%) } \\
\hline Rural & $8(25)$ \\
\hline Semi-urban & $12(37.5)$ \\
\hline Urban & $12(37.5)$ \\
\hline \multicolumn{2}{|c|}{ Religion n (\%) } \\
\hline Hindu & $11(34.375)$ \\
\hline Islam & $21(65.625)$ \\
\hline \multicolumn{2}{|c|}{ Food habit n (\%) } \\
\hline Vegetarian & $4(12.5)$ \\
\hline Non-vegetarian & $28(87.5)$ \\
\hline \multicolumn{2}{|c|}{ Employment status n (\%) } \\
\hline Student & $21(65.625)$ \\
\hline Housewife & $2(6.25)$ \\
\hline Private sector job & $2(6.25)$ \\
\hline Shopkeeper & $2(6.25)$ \\
\hline Unemployment & $5(15.625)$ \\
\hline \multicolumn{2}{|c|}{ BMI n (\%) } \\
\hline Normal weight (18.5-24.9) & $21(65.625)$ \\
\hline Under weight $(<18.5)$ & $9(28.125)$ \\
\hline Over weight (25-29.9) & $2(6.25)$ \\
\hline Obes $(>$ or $=30)$ & $0(0)$ \\
\hline
\end{tabular}

Categorical data presented as absolute values (\%)

Table 2: Medicines prescribed during the study

\begin{tabular}{|c|c|c|c|c|c|c|}
\hline At baseline & At $1^{\text {st }}$ month & At $2^{\text {nd }}$ month & At 3rd month & At $4^{\text {th }}$ month & At $5^{\text {th }}$ month & At $6^{\text {th }}$ month \\
\hline Pulsatilla $(n=8)$ & Pulsatilla $(n=3)$ & Pulsatilla $(n=5)$ & Pulsatilla $(\mathrm{n}=2)$ & Pulsatilla $(n=4)$ & Pulsatilla (n=1) & Pulsatilla $(n=3)$ \\
\hline Natrum mur $(n=6)$ & Nat mur $(n=2)$ & Narummur $(n=1)$ & Ignatia $(n=1)$ & Nat mur $(n=3)$ & Nat mur $(n=4)$ & Nat mur $(n=2)$ \\
\hline Staphysagria $(n=3)$ & Ignatia $(n=2)$ & Sepia $(\mathrm{n}=1)$ & Phsphorus $(\mathrm{n}=1)$ & Staphysagria $(n=1)$ & Causticum $(n=1)$ & Staphysagria $(n=2)$ \\
\hline Causticum $(n=3)$ & Mancinella $(n=1)$ & Causticum $(n=2)$ & Psorinum $(\mathrm{n}=1)$ & Aurum met $(n=1)$ & Mercurious $(n=1)$ & Ignatia $(n=1)$ \\
\hline Ignatia $(n=3)$ & Placebo (24) & Staphysagria $(\mathrm{n}=1)$ & Placebo $(n=27)$ & Sepia $(n=1)$ & Placebo $(n=25)$ & Sepia $(n=1)$ \\
\hline Sepia $(n=2)$ & & Nuxvom $(n=1)$ & & Nuxvom $(n=1)$ & & Placebo $(n=23)$ \\
\hline Aurum met $(n=1)$ & & Placebo $(n=21)$ & & Sulphur $(n=1)$ & & \\
\hline Mancinella $(n=1)$ & & & & Ignatia $(n=1)$ & & \\
\hline Mercurious $(n=1)$ & & & & Placebo $(n=19)$ & & \\
\hline \multicolumn{7}{|l|}{$\operatorname{Nuxvom}(n=1)$} \\
\hline \multicolumn{7}{|l|}{ Phosphorus $(\mathrm{n}=1)$} \\
\hline \multicolumn{7}{|l|}{ Psorinum $(\mathrm{n}=1)$} \\
\hline Sulphur $(n=1)$ & & & & & & \\
\hline
\end{tabular}




\section{Discussion}

Compared to baseline, HDRS-17 score and PHQ-9 scores of participants reduced significantly over six months. As per totality of symptoms, 13 different homoeopathic medicines were used, Pulsatilla nigricans being the most common.

It was observed that many associated symptoms of the patients such as hair fall, headache, constipation, breathing distress were improved, suggesting Homoeopathy as a holistic care of therapeutic method. This study elicited the potential effect of individualized homoeopathic medicines is not only reducing the HDRS-17 score but also improvement in activity and well-being of patients with depression, without any substantial adverse effects. The methodological strengths of the study were its prospective design, use of validated questionnaires such as HDRS-17 and PHQ-9, treatment under qualified and experienced homoeopathic physicians schooled in and practicing classical Homoeopathy in dealing with a challenging condition like depression- a single simple medicine in minimum dose based on totality of symptoms in individualize case. No such published homoeopathic studies on depression could be identified to compare the findings of HDRS-17 and PHQ-9.

\section{Comparison with other studies}

1. Depression in adolescence: from qualitative research to measurement ${ }^{[38]}$

- This study is very short duration i.e., one month pilot study.

- Sample size of this study is very minimum i.e., 29 only.

- This pilot study only for moderate to severe depressive patients not included any mild depressive patients.

- Only medications given in this study. No CBT or psychological counselling do not follow.

2. Study of prevalence of depression in adolescent students of a public school ${ }^{[39]}$

- Only adolescents studying in $9^{\text {th }}$ standard of the school are included in this study. No student in adolescent age of other class is did not included in this study.

- It is a cross-sectional only one-time observational study using simple screening instruments for detecting early symptoms of depression in adolescent age. No treatment or CBR given in this study.

All the acute symptoms of depression were found to be resolved within a span of 15 days only. Amon the used medicines, Pulsatilla nigricans, Natrum muriaticum, Causticum, Ignatia amara, Staphysagria and Sepia was common. The findings were preliminary only and further studies were warranted. The period of study was, however less to evaluate the effect of treatment in reducing the progress of the disease and in preventing acute attacks. In the absence of control arm, there is always chance of overestimation of treatment effect sizes. In comparison, our study was better than this in terms of number of patients, use of validated questionnaires as secondary outcomes, longer duration of follow-ups and comparatively rigorous statistical analysis. Adequately powered randomized controlled trials are warranted to arrive at a definite conclusion regarding the efficacy of Homoeopathic medicines in depression.

\section{Conclusion}

Homoeopathic management has adequate potential in not only alleviating the HDRS-17 score in depression but also a significant role in improving the well-being, activity and quality of life of patients with depression, without adverse effects. This prospective observational trial, though preliminary, revealed a positive treatment effect of individualized homoeopathic medicines in depression. This study findings need to be interpreted with caution and further be experimented in randomized placebo-controlled design with enhanced methodological rigor and longer follow-up.

\section{Acknowledgement}

The authors would like to express their regards to The West Bengal University of Health Sciences for giving the opportunity of carrying out this study. Deep regards to Prof. (Dr.) Samir Kumar Nanda for his guidance in framing the study protocol. A sincere regard to Dr. Subhas Singh, Dr. K. Vijay Ananth, Dr. Abhijit Dutta and Miss Bidisha Mitra for support. We acknowledge the Institutional Ethical Committee, all the visiting physicians, all hospital staff, patients and library staff for their co-operation that provided an opportunity to complete the study.

\section{Financial Support and Sponsorship}

The study was conducted as one of the MD (Hom.) course curriculum of The West Bengal University of Health Sciences.

\section{Conflicts of Interest}

None declared

\section{References}

1. World Health Organization. Depression and other common mental disorders: global health estimates. World Health Organization 2017.

2. Lopez AD, Mathers CD, Ezzati M, Jamison DT, Murray CJ, editors. Global burden of disease and risk factors. The World Bank 2006, 2.

3. Costello EJ, Foley DL, Angold A. 10-year research update review: the epidemiology of child and adolescent psychiatric disorders: II. Developmental epidemiology. Journal of the American Academy of Child \& Adolescent Psychiatry 2006;45(1):8-25.

4. Jane Costello E, Erkanli A, Angold A. Is there an epidemic of child or adolescent depression? Journal of child psychology and psychiatry 2006;47(12):1263-71.

5. Windfuhr K, While D, Hunt I, Turnbull P, Lowe R, Burns $\mathrm{J}$, et al. National Confidential Inquiry into Suicide and Homicide by People with Mental Illness. Suicide in juveniles and adolescents in the United Kingdom. Journal of Child Psychology and Psychiatry 2008;49(11):1155-65.

6. Simon GE, VonKorff M. Suicide mortality among patients treated for depression in an insured population. Am J Epidemiol 1998;147:155-60.

7. Hawton K, van Heeringen K. Suicide. Lancet 2009;373:1372-81.

8. Reus VI. Mental Disorders. In: Fauci AS, Braunwald E, Kasper DL, Longo DL, Hauser SL, Jameson JL, et.al., editors. Harrison's Principles of Internal Medicine, $17^{\text {th }}$ 
ed. Noida, India: Tata McGraw Hill Companies, Inc 2008;2715-6.

9. Charlson FJ, Baxter AJ, Cheng HG, Shidhaye R, Whiteford HA. The burden of mental, neurological, and substance use disorders in China and India: a systematic analysis of community representative epidemiological studies. Lancet 2016;388:376-89.

10. Lewinsohn PM, Rohde P, Seeley JR. Major depressive disorder in older adolescents: prevalence, risk factors and clinical implications. Clin Psychol Rev 1988;18:765-94.

11. Fletcher JM. Adolescent depression and educational attainment: results using sibling fixed effects. Health Econ 2008;17:1215-35.

12. Rayner L, Hotopf M, Petkova H, Matcham F, Simpson A, McCracken LM. Depression in patients with chronic pain attending a specialized pain treatment: prevalence and impact on health care costs. Pain 2016;157(7):1472.

13. Angold A, Costello EJ, Worthman CM. Puberty and depression: the roles of age, pubertal status and pubertal timing. Psychological medicine. Reddy E, Sharma PK, Raj PP. A clinical study on effect of Plantago in gingivitis by assessing bleeding and plaque index 1998;28(1):51-61.

14. Thapar A, Collishaw S, Potter R, Thapar AK. Managing and preventing depression in adolescents. BMJ 2010;340:c209.

15. Lewinsohn PM, Pettit JW, Joiner TE Jr, Seeley JR. The symptomatic expression of major depressive disorder in adolescents and young adults. J Abnorm Psychol 2003;112:244-52.

16. American Psychiatric Association. Diagnostic and statistical manual of mental disorders. 4. Washington DC: American Psychiatric Association 1994.

17. Kessler RC. The costs of depression. Psychiatric Clinics 2012;35(1):1-4.

18. Fava M, Abraham M, Clancy- Colecchi K, Pava JA, Matthews J, Rosenbaum JF. Eating disorder symptomatology in major depression. The Journal of nervous and mental disease 1997;185(3):140-4.

19. Maughan B, Collishaw S, Stringaris A. Depression in childhood and adolescence. Journal of the Canadian Academy of Child and Adolescent Psychiatry 2013;22(1):35.

20. Krishnakumar P, Geeta MG. Clinical profile of depressive disorder in children. Indian Pediatr 2006;43:521-6.

21. ICD-10 Classifications of Mental and Behavioural Disorder: Diagnostic criteria for research. Geneva. World Health Organisation 1993.

22. AFMC; Standard Treatment Guidelines Medical Management \& Costing of Select Conditions; In Collaboration with Ministry of Health \& Family Welfare Government of India \& WHO Country Office, India; Armed Forces Medical College, Pune 2007, 122128.

23. Brown E, Kaiser RM, Gellis ZD. Screening and assessment of late-life depression in home healthcare: Issues and challenges. Annals of Long Term Care 2007;15(10):27.

24. Rush AJ, Nierenberg AA. Mood disorders: Treatment of depression. In: Sadock BJ, Sadock VA, Ruiz P, editors. The Comprehensive Textbook of Psychiatry. 9th ed. Philadelphia: Lippincott Williams and Wilkins 2009; $1: 1734$.

25. Hazell P, O'Connell D, Heathcote D, Henry D. Tricyclic drugs for depression in children and adolescents. Cochrane Database Syst Rev 2002;(2):CD002317.

26. Hughes CW, Emslie GJ, Crismon ML, et al. Texas Children's Medication Algorithm Project: update from Texas Consensus Conference Panel on Medication Treatment of Childhood Major Depressive Disorder. J Am Acad Child Adolesc Psychiatry 2007;46(6):667686.

27. Lewandowski RE, Acri MC, Hoagwood KE, Olfson M, Clarke G, Gardner W, et al. Evidence for the management of adolescent depression. Pediatrics 2013;132(4):e996-1009.

28. Cheung AH, Zuckerbrot RA, Jensen PS, Ghalib K, Laraque D, Stein RE. GLAD-PC Steering Group. Guidelines for adolescent depression in primary care (GLAD-PC): II. Treatment and ongoing management. Pediatrics 2007;120(5):e1313-e1326.35.

29. World Health Organization- Depression Fact sheet 2015; Geneva, Switzerland 2015.

30. Makich L, Hussain R, Humphries JH. Management of depression by homoeopathic practitioners in Sydney, Australia. Complement Ther Med 2007;15:199-206.

31. Davidson JR, Morrison RM, Shore J, Davidson RT, Bedayn G. Homoeopathic treatment of depression and anxiety. Altern Ther Health Med 1997;3:46-9.

32. Pilkington K, Rampes H, Richardson J. Complementary Medicine for Depression. Expert Rev Neurother 2006;6:1741-51.

33. Pilkington K, Kirkwood G, Rampes H, Fisher P, Richardson J. Homoeopathy for depression: A systematic review of the research evidence. Homoeopathy 2005;94:153-63.

34. Davidson JR, Crawford C, Ives JA, Jonas WB. Homoeopathic treatments in psychiatry: A systematic review of randomized placebo: Controlled studies. J Clin Psychiatry 2011;72:795-805.

35. Katz T, Fisher P, Katz A, Davidson J, Feder G. The feasibility of a randomised, placebo- controlled clinical trial of homoeopathic treatment of depression in general practice. Homoeopathy 2005;94:145-52.

36. Mathie RT, Robinson TW. Outcomes from Homoeopathic prescribing in medical practice: A prospective, research- targeted, pilot study. Homoeopathy 2006;95:199-205.

37. Oberai P, Balachandran I, Nair KJ, Sharma A, Singh VP, Singh V, et al. Homoeopathic management in depressive episodes: A prospective, unicentric, noncomparative, open-label observational study. Indian Journal of Research in Homoeopathy 2013;7(3):116.

38. Lachal J, Speranza M, Schmitt A. Spodenkiewicz M, Falissard B, Moto MR, et al. A Depression in adolescence: from qualitative research to measurement. Adolescent Psychiatry 2012;2(4):296-308.

39. Bansal V, Goyal S, Srivastava K. Study of prevalence of depression in adolescent students of a public school. Industrial psychiatry journal 2009;18(1):43. 